\title{
When is the Best Time for Corrective Surgery in Patients with Tetralogy of Fallot between 0 and 12 Months of Age?
}

Izabela F. Martins' ${ }^{1}$, MD; lara C. Doles ${ }^{1}$, MD; Nathalie J. M. Bravo-Valenzuela ${ }^{1,2}$, MD, PhD; Adriana O. R. dos Santos ${ }^{1}$, MD, PhD; Marcela S. P. Varella' ${ }^{1}, \mathrm{MD}, \mathrm{PhD}$

\begin{abstract}
Objective: To identify the best time for corrective surgery of tetralogy of Fallot (TF) in children aged 0-12 months and to report the most frequent complications during the first 3 years postoperatively.

Methods: Systematic review of studies published between 2000 and 2017 on corrective surgery for TF. Articles were selected through search of electronic databases (PubMed, SciELO, Scopus, Lilacs, Google Scholar, and Cochrane). Length of stay in intensive care unit, duration of mechanical ventilation, and peri/
\end{abstract}

postoperative complications were analyzed for data discussion and research interpretation.

Conclusion: Definitive corrective surgery is the best alternative, and the earlier it is performed, the lower the occurrence of harmful effects and the greater the chances of cardiorespiratory recovery. This systematic review suggests that the best time to perform definitive corrective surgery for TF in the first year of life is during 3-6 months of age in children with no or mild symptoms. Children with severe symptoms should undergo surgery immediately.

Keywords: Tetralogy of Fallot/Surgery. Infant, Newborn. Infant.

\begin{tabular}{ll}
\hline \multicolumn{2}{l}{ Abbreviations, acronyms \& symbols } \\
\hline CHD & $=$ Congenital heart disease \\
ECC & $=$ Extracorporeal circulation \\
ICU & $=$ Intensive care unit \\
NYHA & $=$ New York Heart Association \\
RV & $=$ Right ventricle \\
TF & $=$ Tetralogy of Fallot \\
\hline
\end{tabular}

\section{INTRODUCTION}

Tetralogy of Fallot (TF) is the most common cyanogenic congenital heart disease (CHD) occurring after the first year of life and it accounts for approximately $10 \%$ of all $\mathrm{CHD}^{[1]}$. The clinical presentation is variable and the symptoms, such as progressive cyanosis and reduced physical capacity, are directly related to the obstruction of the right ventricle (RV) outflow tract. The natural

\footnotetext{
'Universidade de Taubaté (UNITAU), Taubaté, SP, Brazil.

¿Escola Paulista de Medicina, Universidade Federal de São Paulo (EPM-UNIFESP), São Paulo, SP, Brazil.
}

This study was carried out at the Universidade de Taubaté (UNITAU), Taubaté, SP, Brazil. history of TF is quite variable and is determined by the type and degree of obstruction of the RV outflow tract. Most patients, such as infants, are asymptomatic, but if they are not treated surgically, only $10 \%$ will survive beyond the age of 20 years $^{[2]}$. In contrast, we can expect that $90 \%$ of the patients who undergo definitive surgery in childhood survive up to the fifth decade of life. Without surgical correction, consequences of progressive hypoxemia and acquired changes, such as hypoplasia of the pulmonary arteries and RV and development of collateral systemic pulmonary circulation, will occur. These late changes are the reasons why corrective surgery is being performed earlier and earlier.

In general, early surgery is indicated by the severity of the symptoms and associated injuries. However, attacks of hypoxia, which occur more frequently between 2 and 3 months of age and are not related to the degree of pulmonary stenosis, may evolve with cerebrovascular accidents that may lead to neuro and psychomotor developmental sequelae and death. Thus, there is a current trend toward a preference for definitive correction in

Correspondence Address:

Nathalie J. M. Bravo-Valenzuela

Rua Napoleão de Barros, 875 - Vila Clementino, São Paulo, SP, Brazil Zip code: 04024-002

E-mail:njmbravo@cardiol.br 
cases of TF of good anatomy during the first year of life, aiming to reduce the harmful effects of hypoxemia and to improve the physiological outcome ${ }^{[3]}$. However, the best time to perform this operation remains controversia[ [4,5].

The natural history of TF has undergone major modifications over the last few decades. With the evolution of surgical methods to correct cardiopathies during the neonatal period and the development of specialized intensive care units (ICU), it has been possible to achieve better results at an increasingly earlier age ${ }^{[6,7]}$. These developments directly influenced the earlier indication of correction in children with this condition. In 1973, Barratt-Boyes \& Neutze ${ }^{[8]}$ and Starr et al. ${ }^{[9]}$ showed that TF could be corrected with extracorporeal circulation (ECC) in the first year of life with low morbidity and mortality. In 2005, van Arsdell et al. ${ }^{[10]}$ concluded that the best time for correction of TF was between 3 and 11 months of age based on mortality and better physiological outcome. However, Castañeda et al.!11] indicated accentuated hypoplasia of the pulmonary arteries and anomalous origin of the anterior descending coronary artery (originating from the right coronary artery) as risk factors that could contraindicate definitive correction of this CHD during the first year of life.

Given this context, there is a current trend to prefer definitive correction of classic TF during the firstyear of life instead of correction in two phases (palliative shunt operation and subsequent surgical correction of TF) ${ }^{[12]}$. However, the ideal time for surgical correction of this CHD during the first year of life remains controversial. Age, weight, and clinical condition of the patient, presence or absence of associated extracardiac defects, and experience of the service where the operation will be performed in addition to a careful evaluation of the cardiac anatomy of each patient (characteristics of the RV outflow tract, pattern of coronary circulation, and analysis of the ventricles) are factors that must be considered for an indication of the best time for the correction of this $\mathrm{CHD}^{[13,14]}$.

In this study, we systematically reviewed relevant studies published between 2000 and 2017, including those in which definitive correction of TF was performed during the first year of life. We considered peri- and postoperative mortality and complications, such as duration of ECC, arrhythmias, ventricular dysfunction, and pulmonary insufficiency and/or stenosis requiring surgical reintervention, to conclude which is the best time for this operation. Moreover, we discussed the unfavorable factors of the cardiac anatomy and small body surface area $\left(<0.46 \mathrm{~m}^{2}\right)$, which are considered risk factors for the correction of classic TF.

\section{METHODS}

\section{Sources of Electronic Searches}

This systematic review was performed on 5 steps according to Khan et al..15]: step 1 - the review question, step 2 - study selection, step 3 - quality assessment of the studies, step 4 data synthesis, and step 5 - interpreting the findings. The search was based on the following question: "When is the best time for corrective surgery in patients with Tetralogy of Fallot between 0 and 12 months of age". The electronic search for articles published from 2000 to November 2017 in the PubMed/Medline, SciELO, Lilacs, Google Scholar, Cochrane, and Scopus databases was conducted without language restriction (Figure 1). However, the descriptors were used both in English and in Portuguese: "Tetralogy of Fallot", "surgery", "newborn", and "infant".

\section{Study Selection}

The titles and abstracts of all publications obtained from the electronic search and their lists of references were screened extensively by the authors. The pre-established inclusion and exclusion criteria were applied, and articles with complete texts were selected to be examined and included in this review. Indeed, the studies selected were assigned according to the research design's quality, such as homogeneous or heterogeneous populations, bias adjustment factors, short or long-term followup, and prospective or retrospective study.

\section{Selection Criteria}

Studies published between 2000 and 2017 on corrective surgery in patients younger than 12 months of age who presented with the classic TF were included. Patients with pulmonary atresia or other cardiac or associated extracardiac malformations were excluded. Duplicate studies and those with possible design bias or poor-quality design on safety were excluded (Figure 1). Indeed, cases studies and opinion of experts were not included.

\section{RESULTS}

\section{Selected Studies}

The electronic search retrieved a total of 2,316 records that were displayed based on their titles and abstracts. Of these, 55 were selected based on their titles and abstracts. Thirty-three publications were excluded because they did not meet the selection criteria, remaining 22 articles eligible for the study (Figure 1).

\section{Studies' Characteristics}

There was a total of 20 cohort studies and two bibliographical reviews (Table 1). Twenty articles were published in English and two in Portuguese. Studies were conducted in the United States of America, four in Germany, four in Canada, in the United Kingdom, two in Brazil, one in Turkey, one in Austria, and one in Korea.

In the 20 cohort studies, 6,801 definitive correction surgeries for TF were performed, all in patients younger than 12 months of age. The mean mortality rates of the 22 studies (after the 50's) were $1.99 \%$ and $4.55 \%$ for neonates.

The main perioperative complications found were enlargement of the outflow tract, most commonly the placement of a transannular patch (44.5\% in patients from 1 to 12 months and 66 to $100 \%$ in neonates), prolonged ECC, and cardiorespiratory arrest during surgery.

The most frequently reported postoperative complications after 3 years of follow-up were arrhythmia, ventricular dysfunction, and pulmonary insufficiency, ranging from mild to severe.

\section{DISCUSSION}

Over the past two decades, the number of definitive repairs performed has increased significantly, with early repair 
Excluded

33 studies

*21 did not meet the eligibility

criteria

*12 were duplicates
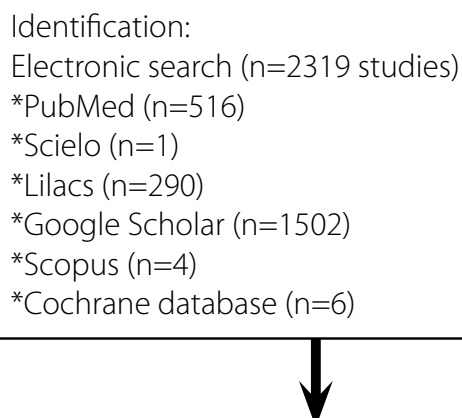

Screening

55 studies were selected by title and abstract

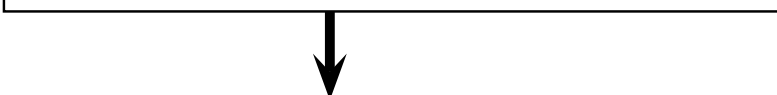

Eligibility

22 studies were evaluted for eligibility in their entirety

\begin{tabular}{l|}
\hline Included \\
22 studies* \\
$* 20$ retrospective studies \\
$* 2$ review studies
\end{tabular}

Fig. 1 - Flowchart of records identified after an electronic search (by title and abstract) of articles published during 2000-2017 on the surgical correction of tetralogy of Fallot performed during the first year of life.

becoming increasingly common. All the 22 articles stated that definitive surgery for TF performed in patients younger than 1 year of age offers numerous advantages over that performed in patients after this age.

Early normalization of cardiovascular physiology with consequent reduction in secondary damage, reduction in the harmful effects of chronic hypoxemia present in patients with $T F$, and minimization of ventricular hypertrophy are some of the benefits of performing surgery in patients younger than 1 year of age. In addition, the morbimortality of systemic pulmonary shunts has been practically eliminated.

Several authors such as Kolcz and Pizarro[16] advocate early repair because it favors the growth of the pulmonary artery, which becomes capable of providing blood flow and alveolar growth to the child. Two other authors, Park et al. ${ }^{[17]}$ and Kaulitz et al. ${ }^{[18]}$, demonstrated growth and increased diameter of the pulmonary arteries when the first surgery to repair TF was performed during the first year of life. In the study by Park et al. ${ }^{[17]}$, the growth of the pulmonary arteries after restoration of blood flow was evaluated based on the Nakata index using transthoracic echocardiography instead of cardiac catheterization to conduct the measurements (Nakata index = ratio between the sum of the areas of the pulmonary arteries and the body surface area, expressed in $\mathrm{mm}^{2}$ per $\left.\mathrm{m}^{2}\right)^{[19]}$. This study, using the quantitative method, corroborated the conclusion that early surgical correction of TF in a single stage contributes to a greater growth of pulmonary arteries than palliative surgery and in the second stage of correction, it reduces the risk of surgical reintervention or short-term reoperation ${ }^{[17]}$.

Mortality in children with definitive early repair is markedly lower. A study conducted by Gerling et al. ${ }^{[20]}$ in Germany reported a mortality of $3.2 \%$ in patients younger than 12 months of age compared with $12.9 \%$ in those older than that.

Another study, from Germany, by Bakhtiary et al.. ${ }^{[21]}$ presented the observed long-term benefits. It was conducted with 120 children who underwent surgery at younger than 1 year of age. It was shown that $80 \%$ of the children were in New York Heart Association (NYHA) class 1 at the end of the study and remained off antiarrhythmic drugs at 10 years of postoperative follow-up. Similarly, in a study by Alexiou et al. ${ }^{[22]}, 86$ of the 89 patients who underwent surgery before 12 months of age remained in NYHA 1 without the use of antiarrhythmic drugs in the postoperative period.

None of the studies reported an increased mortality in surgical reintervention of patients younger than 6 months of age. However, of the 20 evaluated articles, 50\% reported a higher surgical risk in children younger than 3 months of age. Vohra HA et al. ${ }^{[23]}$ and van Dongen et al. ${ }^{[24]}$ showed that patients younger than 3 months of age had longer hospital and ICU stays, a greater need for the use of inotropes and for volume replacement, and a higher incidence of organ dysfunction.

Park et al. ${ }^{[17]}$ and Parry et al. ${ }^{[25]}$ demonstrated that an early repair of TF may allow normal RV outflow tract growth thereafter. 
Table 1. Main studies indicating the optimal age (from birth until 12 months) for correction of tetralogy of Fallot (TF).

\begin{tabular}{|c|c|c|c|c|c|}
\hline Author, year & Study design & Study period & $\begin{array}{c}\text { Number } \\
\text { of surgical } \\
\text { complete repairs }\end{array}$ & $\begin{array}{l}\text { Early surgical } \\
\text { mortality }\end{array}$ & $\begin{array}{c}\text { Conclusion (optimal age for surgical } \\
\text { repair of TF) }\end{array}$ \\
\hline Barron ${ }^{[5]}, 2013$ & $\begin{array}{l}\text { Retrospective } \\
\text { Multicenter }\end{array}$ & 2002 to 2007 & $\begin{array}{l}3000 \\
178 \text { neonatal } \\
\text { repairs }\end{array}$ & $\begin{array}{c}1.9 \text { to } 3 \% \\
7.8 \% \text { (neonates) }\end{array}$ & Optimal age: 3 to 9 months \\
\hline Kirsch et al. ${ }^{[30]}, 2014$ & $\begin{array}{l}\text { Retrospective } \\
\text { Single-center }\end{array}$ & 1995 to 2009 & 277 & - & Optimal age: 3 to 6 months \\
\hline Gerrah et al. ${ }^{[14]}, 2015$ & $\begin{array}{l}\text { Retrospective } \\
\text { Single-center }\end{array}$ & 2005 to 2013 & 51 & - & $\begin{array}{c}\text { Primary surgical repair for correction of TF has } \\
\text { a more favorable outcome than palliation in } \\
\text { children weighing less than } 4 \mathrm{~kg}\end{array}$ \\
\hline Park et al. ${ }^{[17]}, 2010$ & $\begin{array}{l}\text { Retrospective } \\
\text { Single-center }\end{array}$ & 2000 to 2008 & 13 & - & $\begin{array}{l}\text { Optimal age: less than } 3 \text { months, earlier } \\
\text { surgical correction of TF may be better for } \\
\text { the pulmonary artery growth }\end{array}$ \\
\hline Kantorova et al. ${ }^{[31]}, 2008$ & $\begin{array}{l}\text { Retrospective } \\
2 \text { institutions }\end{array}$ & 1996 to 2006 & 61 & $1.63 \%$ & $\begin{array}{l}\text { Optimal age for asymptomatic patients: } \\
\text { more than } 3 \text { months. } \\
\text { Optimal age for symptomatic patients: as } \\
\text { early as possible }\end{array}$ \\
\hline Alexiou et al. ${ }^{[22]}, 2001$ & $\begin{array}{l}\text { Retrospective } \\
\text { Single-center }\end{array}$ & 1974 to 2000 & 89 & $1.1 \%$ & Optimal age: within 12 months \\
\hline Egbe et al. ${ }^{[6]}, 2014$ & $\begin{array}{l}\text { Retrospective } \\
\text { Single-center }\end{array}$ & 2001 to 2012 & 97 & - & $\begin{array}{l}\text { Age and weight are independent predictors } \\
\text { of morbidity }\end{array}$ \\
\hline Van Arsdell et al. ${ }^{[4]}, 2000$ & $\begin{array}{l}\text { Retrospective } \\
\text { Single-center }\end{array}$ & 1996 to 1998 & 227 & (0 to $12 \mathrm{~m})$ & Optimal age: 3 to 11 months \\
\hline Van Arsdell et al. ${ }^{[10]}, 2005$ & $\begin{array}{c}\text { Review } \\
\text { Single-center }\end{array}$ & 1996 to 2004 & 357 & $0.6 \%$ & Optimal age: 3 to 6 months \\
\hline Parry et al. ${ }^{[25]}, 2000$ & $\begin{array}{l}\text { Retrospective } \\
\text { Single-center }\end{array}$ & 1992 to 1999 & 42 & - & Optimal age: before 3 months \\
\hline Moraes Neto et al.[28], 2008 & $\begin{array}{l}\text { Retrospective } \\
\text { Single-center }\end{array}$ & 1996 to 2004 & 67 & $2.98 \%$ & Optimal age: before 12 months \\
\hline Moraes Neto et al. ${ }^{[27]}, 2000$ & $\begin{array}{l}\text { Retrospective } \\
\text { Single-center }\end{array}$ & 1986 to 1999 & 30 & $6.6 \%$ & $\begin{array}{l}\text { Optimal age: before } 12 \text { months. Expansion of } \\
\text { the outflow tract involved in right ventricular } \\
\text { obstruction and transannular patch as a risk } \\
\text { factor in body surface areas }<0.48 \mathrm{~m}^{2}\end{array}$ \\
\hline Kaulitz et al. ${ }^{[18]}, 2001$ & $\begin{array}{l}\text { Retro- and } \\
\text { prospective } \\
\text { Single-center }\end{array}$ & $\begin{array}{l}\text { Follow-up } 80,4 \\
\pm 24 \text { months }\end{array}$ & 62 & $4.8 \%$ & Optimal age: from 3 to 12 months \\
\hline Steiner et al. ${ }^{[13]}, 2014$ & $\begin{array}{l}\text { Retrospective } \\
\text { Multicenter }\end{array}$ & 2004 to 2010 & 4698 & $\begin{array}{c}1.3 \% \\
6.4 \% \text { (neonates) }\end{array}$ & Optimal age: from 3 to 12 months \\
\hline Starr ${ }^{[29]}, 2010$ & Review & 1952 to 2010 & 2715 & $\begin{array}{c}\text { 50's: } 60 \% \\
\text { Early } 60 \text { 's: } 5-14 \% \\
70 \text { 's to } 2009:<2 \%\end{array}$ & $\begin{array}{c}\text { From 70's to present: complete repair of TF is } \\
\text { performed before } 6 \text { months of age with low } \\
\text { mortality. }\end{array}$ \\
\hline Kolcz \& Pizarro[16], 2005 & $\begin{array}{l}\text { Retrospective } \\
\text { Single-center }\end{array}$ & 1998 to 2004 & 66 & $4.5 \%$ & $\begin{array}{c}\text { Elective repair of TF in neonates has } \\
\text { excellent results. Preoperative weight }< \\
2.5 \mathrm{~kg} \text { and small left pulmonary artery size } \\
\text { are associated with higher incidence of } \\
\text { reintervention }\end{array}$ \\
\hline Bakhtiary et al. ${ }^{[21]}, 2013$ & $\begin{array}{l}\text { Retrospective } \\
\text { Single-center }\end{array}$ & 1998 to 2009 & 120 & - & Optimal age: up to 4 months \\
\hline Al Habib et al. ${ }^{[7]}, 2010$ & $\begin{array}{l}\text { Retrospective } \\
\text { Multicenter }\end{array}$ & 2002 to 2007 & 2534 & $\begin{array}{c}1.3 \% \\
7.8 \% \text { (neonates) }\end{array}$ & Optimal age: before 12 months \\
\hline Wilder et al. ${ }^{[12]}, 2017$ & $\begin{array}{l}\text { Retrospective } \\
\text { Single-center }\end{array}$ & 2000 to 2012 & 453 & $0.67 \%$ & Optimal age: 3 to 9 months \\
\hline Gerling et al. ${ }^{[20]}, 2009$ & $\begin{array}{l}\text { Retrospective } \\
\text { Single-center }\end{array}$ & 1992 to 2003 & 124 & $4.8 \%$ & Optimal age: from 3 to 12 months \\
\hline
\end{tabular}

Continues 


\begin{tabular}{l|l|c|c|c|c}
\hline Ooi et al. ${ }^{[33]}, 2006$ & $\begin{array}{l}\text { Retrospective } \\
\text { Single-center }\end{array}$ & 1997 to 2003 & 52 & $1.9 \%$ & Optimal age: 3 to 6 months \\
\hline Tamesberger et al. ${ }^{[34]}, 2008$ & $\begin{array}{l}\text { Retrospective } \\
\text { Single-center }\end{array}$ & 1995 to 2006 & 90 & $\begin{array}{c}\text { Neonatal primary surgical repair is associated } \\
\text { with more frequent use of transannular patch } \\
\text { and reinterventions }\end{array}$ \\
\hline
\end{tabular}

However, the need for enlargement of the outflow tract was more often observed in patients younger than 3 months of age when comparing the studies reviewed. In the study conducted at the Slovak Pediatric Heart Center, in Bratislava, and at the University Hospital Hamburg-Eppendorf, 61 children underwent definitive surgery and $85 \%$ of those younger than 3 months of age required the placement of a transannular patch as opposed to $61 \%$ of those older than that ${ }^{[26]}$. On the other hand, $35 \%$ of the articles in the review showed that the age limit for good results, both in short and long terms, is 6 months.

According to a cohort study by Moraes Neto et al.[.27], the need for enlargement of the outflow tract may compromise the late postoperative period, and the placement of a transannular patch is a significant risk factor in children with body surface area $<0.48 \mathrm{~m}^{2}$. Based on the evaluation criteria of perioperative complications in that review, the necessity of enlargement of the outflow tract is a factor to be considered when determining the best age for surgery ${ }^{[28]}$.

In the cohort study by Moraes Neto et al. ${ }^{[27]}, 56$ children were divided into two groups, with one of the groups comprising children between 3 and 11 months of age who underwent definitive corrective surgery. In this group, $73.3 \%$ of the patients required enlargement of the right ventricular outflow tract and $50 \%$ of them required transannular patch repair. Of these $50 \%$, 10 were children older than 6 months of age and only 5 were younger than 6 months of age.

Overall mortality was higher in children older than 6 months of age. In a cohort study presented by Steiner et al. ${ }^{[13]}$, a mortality rate of $0.7 \%$ was observed in children between 3 and 6 months of age as compared with $6.4 \%$ in those younger than 30 days of age, $1.9 \%$ in those between 31 days and 3 months of age, and $1.1 \%$ in those older than 6 months of age.

Van Arsdell et al. ${ }^{[10]}$ demonstrated that surgery performed at 6 months of age is very well tolerated, with little development of restrictive physiology, minimal need for prolonged ventilation time, and no development of ascites. The deaths reported were of patients with primary repair after 12 months of age. They also state that neonatal repair does not appear to be the best strategy because of greater development of physiological restriction, higher incidence of stroke, and, in general, longer mechanical ventilation and ICU length of stay.

In a study titled "Tetralogy of Fallot: Yesterday and Today," the author, Starr JP, supports a concept that has been around since 1970: the best age for definitive repair is before 6 months of age ${ }^{[29]}$. This study shows a mortality rate of $2 \%$ and a long-term survival rate ranging from $58 \%$ to $90 \%$. In addition, the author reports that initial survival following definitive repair of TF ranges from $98 \%$ to $100 \%$. The study does not recommend exceeding a maximum of 12 months of age. Indeed, Kirsch et al. ${ }^{[30]}$ demonstrated that the best age for surgical correction of TF is between 3 and 6 months and Kantorova et al. ${ }^{[3]]}$ concluded that the optimal age for the complete surgical repair for asymptomatic TF patients is after 3 months.

Barron et al. ${ }^{[5]}$ and Steiner et al. ${ }^{[13]}$ demonstrated that the mortality for primary repair was higher in neonates with TF when compared to infants older than 30 days of age ${ }^{[15]}$. Controversially, there were no differences in post-operative age-related mortality in the studies conducted by Loomba et al.[32] and Ooi et al. ${ }^{[33]}$. Meanwhile, Van Arsdell et al[. ${ }^{[10]}$ and Tamesberg et al. ${ }^{[34]}$ showed that neonatal surgical primary repair for TF was associated with longer total hospital length of stay, more frequent use of transannular patch, and reinterventions. Furthermore, preoperative weight $<2.5 \mathrm{~kg}$ and small left pulmonary artery size are associated with higher incidence of reintervention ${ }^{[16]}$.

\section{CONCLUSION}

With advances in medicine, the guarantee of quality of life for children diagnosed with TF has become a reality. Definitive surgical correction is the best choice, and the earlier the treatment, the lower the occurrence of harmful effects and the greater the chance of cardiorespiratory recovery.

The best age for performing definitive corrective surgery for TF is still a topic of discussion in cardiology and pediatric cardiac surgery. Based on this careful systematic review - our analysis of all the articles, considering a postoperative period of up to 3 years, length of stay in ICU, duration of mechanical ventilation, peri- and postoperative complications, need for reoperation, and mortality -, we concluded that the best age for elective definitive surgical correction of TF is between 3 and 6 months of age in asymptomatic and mildly symptomatic children. Children with severe symptoms should undergo surgery immediately, regardless of age.

\section{Authors' roles \& responsibilities}

IFM Collecting the and interpretation of data for the work; final approval of the version to be published

ICD Collecting the and interpretation of data for the work; final approval of the version to be published

NJMBV Conception or design of the work; revising it critically for important intellectual content; final approval of the version to be published

AORS Revising it critically for important intellectual content; final approval of the version to be published

MSPV Revising it critically for important intellectual content; final approval of the version to be published 


\section{REFERENCES}

1. Bailliard F, Anderson RH. Tetralogy of Fallot. Orphanet J Rare Dis. 2009;4:2.

2. Freedom RM, Yoo SJ. Tetralogy of Fallot. In: Freedom RM, Yoo SJ, Mikailian $\mathrm{H}$, Williams WG, eds. The natural and modified history of congenital heart disease. New York: Futura; 2004. p.186-211.

3. Hennein HA, Mosca RS, Urcelay G, Crowley DC, Bove EL. Intermediate results after complete repair of tetralogy of Fallot in neonates. J Thorac Cardiovasc Surg. 1995;109(2):332-42.

4. Van Arsdell GS, Maharaj GS, Tom J, Rao VK, Coles JG, Freedom RM, et al. What is the optimal age for repair of tetralogy of Fallot? Circulation. 2000;102(19 Suppl 3):III123-9.

5. Barron DJ. Tetralogy of Fallot: controversies in early management. World J Pediatr Congenit Heart Surg. 2013;4(2):186-91.

6. Egbe AC, Uppu SC, Mittnacht AJ, Joashi U, Ho D, Nguyen K, et al. Primary tetralogy of Fallot repair: predictors of intensive care unit morbidity. Asian Cardiovasc Thorac Ann. 2014;22(7):794-9.

7. Al Habib HF, Jacobs JP, Mavroudis C, Tchervenkov Cl, O'Brien SM, Mohammadi $S$, et al. Contemporary patterns of management of tetralogy of Fallot: data from the Society of Thoracic Surgeons Database. Ann Thorac Surg. 2010;90(3):813-9.

8. Barratt-Boyes BG, Neutze JM. Primary repair of tetralogy of Fallot in infancy using profound hypothermia with circulatory arrest and limited cardiopulmonary bypass: a comparison with conventional two stage management. Ann Surg. 1973;178(4):406-11.

9. Starr A, Bonchek LI, Sunderland CO. Total correction of tetralogy of Fallot in infancy. JThorac Cardiovasc Surg. 1973;65(1):45-57.

10. Van Arsdell G, Yun TJ. An apology for primary repair of tetralogy of Fallot. Semin Thorac Cardiovasc Surg Pediatr Card Surg Annu. 2005:128-31.

11. Castaneda AR, Mayer JE Jr, Jonas RA, Lock JE, Wessel DL, Hickey PR. The neonate with critical congenital heart disease: repair: a surgical challenge. J Thorac Cardiovasc Surg. 1989;98(5 Pt 2):869-75.

12. Wilder TJ, Van Arsdell GS, Benson L, Pham-Hung E, Gritti M, Page A, et al. Young infants with severe tetralogy of Fallot: early primary surgery versus transcatheter palliation. J Thorac Cardiovasc Surg. 2017;154(5):1692-700.

13. Steiner MB, Tang X, Gossett JM, Malik S, Prodhan P. Timing of complete repair of non-ductal-dependent tetralogy of Fallot and short-term postoperative outcomes, a multicenter analysis. JThorac Cardiovasc Surg. 2014;147(4):1299-305.

14. Gerrah R, Turner ME, Gottlieb D, Quaegebeur JM, Bacha E. Repair of tetralogy of Fallot in children less than $4 \mathrm{~kg}$ body weight. Pediatr Cardiol. 2015;36(7):1344-9.

15. Khan KS, Kunz R, Kleijnen J, Antes G. Five steps to conducting a systematic review. J R Soc Med. 2003;96(3):118-21.

16. Kolcz J, Pizarro C. Neonatal repair of tetralogy of Fallot results in improved pulmonary artery development without increased need for reintervention. Eur J Cardiothorac Surg. 2005;28(3):394-9.

17. Park CS, Kim WH, Kim GB, Bae EJ, Kim JT, Lee JR, et al. Symptomatic young infants with tetralogy of Fallot: one-stage versus staged repair. J Card Surg. 2010;25(4):394-9.

18. Kaulitz R, Jux C, Bertram H, Paul T, Ziemer G, Hausdorf G. Primary repair of tetralogy of Fallot in infancy: the effect on growth of the pulmonary arteries and the risk for late reinterventions. Cardiol Young. 2001;11(4):391-8.

19. Nakata S, Imai Y, Takanashi Y, Kurosawa H, Tezuka K, Nakazawa M, et al. A new method for the quantitative standardization of cross-sectional areas of the pulmonary arteries in congenital heart diseases with decreased pulmonary blood flow. J Thorac Cardiovasc Surg. 1984;88(4):610-9.

20. Gerling C, Rukosujew A, Kehl HG, Tjan TD, Hoffmeier A, Vogt J, et al. Do the age of patients with tetralogy of Fallot at the time of surgery and the applied surgical technique influence the reoperation rate. A single-center experience. Herz. 2009;34(2):155-60.

21. Bakhtiary F, Dähnert I, Leontyev S, Schröter T, Hambsch J, Mohr FW, et al. Outcome and incidence of re-intervention after surgical repair of tetralogy of Fallot. J Card Surg. 2013;28(1):59-63.

22. Alexiou C, Mahmoud H, Al-Khaddour A, Gnanapragasam J, Salmon AP, Keeton BR, et al. Outcome after repair of tetralogy of Fallot in the first year of life. Ann Thorac Surg. 2001;71(2):494-500.

23. Vohra HA, Adamson L, Haw MP. Is early primary repair for correction of tetralogy of Fallot comparable to surgery after 6 months of age? Interact Cardiovasc Thorac Surg. 2008;7(4):698-701.

24. van Dongen El, Glansdorp AG, Mildner RJ, McCrindle BW, Sakopoulos AG, VanArsdell G, et al. The influence of perioperative factors on outcomes in children aged less than 18 months after repair of tetralogy of Fallot. J Thorac Cardiovasc Surg. 2003;126(3):703-10.

25. Parry AJ, McElhinney DB, Kung GC, Reddy VM, Brook MM, Hanley FL. Elective primary repair of acyanotic tetralogy of Fallot in early infancy: overall outcome and impact on the pulmonary valve. J Am Coll Cardiol. 2000;36(7):2279-83.

26. Kantorova A, Zbieranek K, Sauer H, Lilje C, Haun C, Hraska V. Primary early correction of tetralogy of Fallot irrespective of age. Cardiol Young. 2008;18(2):153-7.

27. Moraes Neto F, Gomes CA, Lapa C, Hazin S, Tenório E, Mattos S, et al. Surgical treatment of Fallot in the first year of life. Braz J Cardiovasc Surg. 2000:15(2):143-53.

28. Moraes Neto FR, Santos CC, Moraes CR. Intracardiac correction of tetralogy of Fallot in the first year of life: short-term and mid-term results. Rev Bras Cir Cardiovasc. 2008;23(2):216-23.

29. Starr JP.Tetralogy of Fallot:yesterday and today. World J Surg. 2010;34(4):658-68. 30. Kirsch RE, Glatz AC, Gaynor JW, Nicolson SC, Spray TL, Wernovsky G, et al. Results of elective repair at 6 months or younger in 277 patients with tetralogy of Fallot: a 14-year experience at a single center. J Thorac Cardiovasc Surg. 2014;147(2):713-7.

31. Kantorova A, Zbieranek K, Sauer H, Lilje C, Haun C, Hraska V. Primary early correction of tetralogy of Fallot irrespective of age. Cardiol Young. 2008;18(2):153-7.

32. Loomba RS, Buelow MW, Woods RK. Complete repair of tetralogy of Fallot in the neonatal versus non-neonatal period: a meta-analysis. Pediatr Cardiol. 2017;38(5):893-901.

33. Ooi A, Moorjani N, Baliulis G, Keeton BR, Salmon AP, Monro JL, et al. Medium term outcome for infant repair in tetralogy of Fallot: Indicators for timing of surgery. Eur J Cardiothorac Surg. 2006;30(6):917-22.

34. Tamesberger MI, Lechner E, Mair R, Hofer A, Sames-Dolzer E, Tulzer G. Early primary repair of tetralogy of Fallot in neonates and infants less than four months of age. Ann Thorac Surg. 2008;86(6):1928-35. 